\title{
Meaning and Association
}

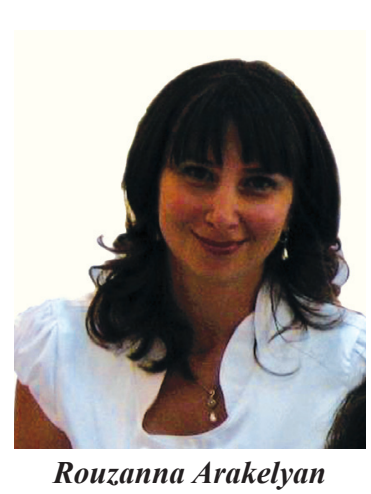

Associationists have been concerned with the relative innateness of psychological processes and the contents of the mind. They typically side with those who feel that most of these processes and contents are learned. (Boring 1950:29) On the opposite side are those who speak mainly of innate mental organizers, ideas, and the like, and who also tend to be non-associationistic in their thinking.

Experimental psychologists from the time of Wundt and Ebbinhaus have considered meaning to be the function of associations. One thing could have meaning only if it was associated with something else; the nature of meaning depended on the particular associations and the multiplicity of associations involved. It should be noted that these early theorists used the term "association" in a more or less technical sense. In other words, associations were interpreted as important links between ideas or between sensations. The desire for more precise experimental investigations of psychological problems led to the idea of measuring the number and the kinds of associations. The relationship between associations and learning is by no means a universally accepted conclusion. It should be realized that something's having association with another thing is not identical with its having meaning in a non-linguistic sense.

In psychology and psychiatry associations are used for the study of human behaviour and mentality whereas psycholinguists are interested in the study of verbal associations to understand the peculiarities of mentality and its verbal expression.*

There are two basic ways of measuring associations to words. The first method expounded by Kent and Rosanoff is regarded as the method studying the situation when the subject is presented with a stimulus word and asked to respond with the first word he thinks of. (Terwillinger 1968:166) When talking about the nature of associations, we need to refer to associations given by a large number of subjects to a large list of stimuli. The degree of commonness of the most typical responses varies from word to word but in some cases may exceed 80 per cent. In other words, it is not unusual for a vast majority of the subjects to agree upon the association given. Words vary in their distributions of associations - some words reliably have associations more equal in their frequency of occurrence than others. 
It is much more difficult to be precise about the qualitative nature of the associations given. We find that synonyms (cross-angry, glad-happy, merry-happy, boring-dull, attractive-pretty, astonished-puzzled, beautiful-pretty) and antonyms of the stimuli (good-bad, interesting-dull, happy-unhappy, handsome-ugly, sad-happy) are the most common associations. To some extent it is possible to divide associations into two categories: those which reflect or respond to the referential characteristics of the word, and those that reflect its uses in utterances. It is worth mentioning that the first type of associations is more common in children rather than adults.

Very often subjects reflect certain mood or evaluative judgements which are beyond the understanding of experimental psycholinguists partly because they are not associations which are relevant to the common social uses of language. Among such are the cases when the subject responds with a proper name to a stimulus word (surprised-Newton). It should be noted that there are subjects who clearly ignore the instructions and give associations which represent non-uses of the word in order to confuse the experimenter. What they fail to realize is that by doing so they are giving data potentially as useful as that given by more co-operative subjects. When subjects, consciously or unconsciously, give words that are not associates of the stimulus, they define the meaning of the word as accurately as if they gave associates consciously. This phenomenon occurs because the meaning of words can also be defined in contexts in which the word is not used. No verbal subject can remain independent of verbal stimuli; he may obey or ignore instructions, but he responds to the stimuli nevertheless.

In the other association method the subject is given a stimulus word and asked to give as many associations to it as he can within a given period of time. The results are presented in terms of the average number of associations given by the average subject. This method has obvious advantages as a simple description of meaningfulness or the quantity of associations. It should also be mentioned that the method described has one methodological drawback: one can't be sure that the experimentee is always really responding to the stimulus word. It is possible that the subject is giving first an association to the stimulus word, and then an association to the first reaction. These types of associations are usually based on phonetic similarities (calm-sum, dumb, luckyfeeling, dealing). This is called chaining of associations which is of little importance to the expert if he is not interested in the quantity of responses.

In "free-association" method the stimuli are removed from any normal context in which they might ordinarily be used. But they are not free of contextual effects. According to Kent-Rosanoff's approach to associations as indicators of personality variables, they are determined by idiosyncratic contexts chosen by the participants of the experiments.

The association methods while equally permissive with respect to context, permit the subject to "use" the word, or respond to it, in any way he chooses - providing, of course, that the response is another single word. The responses obtained, then, could be more relevant to the actual use of the word and it would seem that a subject might tend to use the word in a way in which he was accustomed to using it, providing that the 
instructions for the associations obtained in the so-called free-association studies may well reflect or be related to the actual use of the stimuli.

It is also clear that verbal associations do not represent the totality of what we would call the meaning of a word. These associations are indeed uses of the word, but they are uses made in the restricted environment of the psychology laboratory. It would be right to say that, in general, the associations obtained from the subject in the association method represent a set of verbal descriptions of how the subject uses the words. The associatons are clearly related to the meaning of the words. Thus, the assumption that a word which is used in different ways will call out different verbal descriptions of those uses. Accordingly, it is true that the number of different verbal descriptions will be proportional to the number of different uses. (Popova 2006:12)

There are two different situations in which we must evaluate the above mentioned assumption. First, let us consider the case in which the subject gives many responses to a single stimulus. Here it seems quite safe to assume that the more meanings a word has for the subject, the more verbal description he will give of it. Presumably we might infer something about the number of meanings from the number of responses given.

When each subject gives one response per stimulus, the number of different descriptions is determined across subjects, rather than within one subject. If we assume that an individual has several possible uses for a word and he must pick one of them to use in an otherwise ambiguous situation, there are certain things we expect to find. If we presume that some uses are more common than others, we might assume that he would pick accordingly from among the possible varieties. In a large number of subjects, the probability distribution would be identical to the individual. So if language is to function as language, it must be shared by members of the linguistic society. Since social agreement is by definition a characteristic of language, we might expect to find agreement among associations as well. (Zif 1960:68)

We assume that the number of different associations given by either association method is proportional to the amount of the stimulus word. Likewise, the obtained probability of any given association is proportional to the probability of the particular word use that the association in question describes.

It becomes clear that verbal associations do not directly constitute meaning; they are in reality descriptions of meaning or use. We propose to be neutral about how much of the mind is learned and postulate the following idea: whether it is learned or innate, it is properly describable in associationistic language.

\section{Notes:}

* One of Ch.Darwin's cousins, sir F.Galton, was the first to conduct a psycholinguistic experiment. He chose 75 words, wrote them down on separate cards and did not touch them for a few days. Then he took the cards and looked at them for some time trying to define how much time passed since his seeing the word and the first reactions coming to his mind. He wrote down the reactions, but 
never published them, because he thought that it would uncover the essence of man's mind so vividly and truthfully that it would become world's property. Since then this method has been widely used by psychologists and psychiatrists, and later on by psycholinguists for the purpose of studying personality's psychics and mentality.

\section{References:}

1. Boring, E.G. (1950) A History of Experimental Psychology. New York: Academic Press.

2. Popova, T. (2006) Assostiatsivniy Eksperiment v Psikhologii. Moscow: Prospect.

3. Terwillinger, R. (1968) Meaning and Mind: A Study in the Psychology of Language. New-York-London: Oxford University Press.

4. Zif, P. (1960) Semantic Analysis. Hove: Cornell University Press.

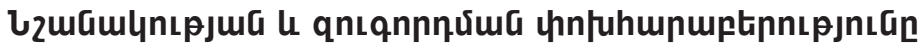

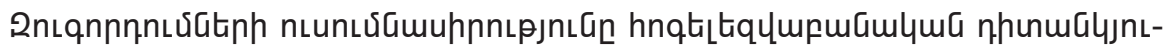

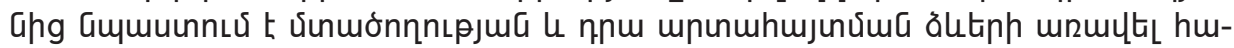

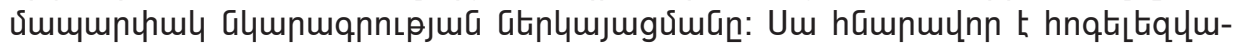

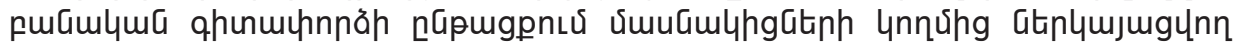

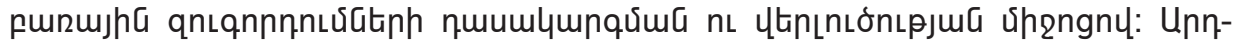

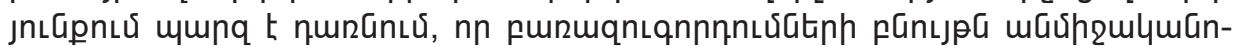

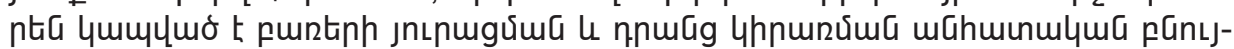

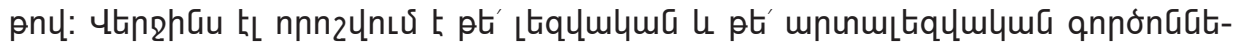

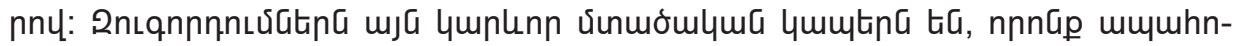

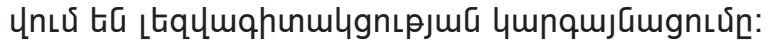

